\title{
Prognosis of Percutaneous Intervention of a Left Main Coronary Artery Stenosis Without the Use of Intravascular Imaging
}

Mazhar Mahmood ${ }^{1}$, Afrasyab Altaf ${ }^{2}$, Momin Salahuddin ${ }^{1}$, Momin Khan ${ }^{1}$, Karamat A. Shah ${ }^{1}$ , Hammad Shah ${ }^{1}$

1. Department of Cardiology, Rehman Medical Institute, Peshawar, PAK 2. Cardiology, Rehman Medical Institute, Peshawar, PAK

$\square$ Corresponding author: Afrasyab Altaf, afrasyabaltaf@gmail.com Disclosures can be found in Additional Information at the end of the article

\section{Abstract}

\section{Objectives}

The aim of this study was to assess the prognosis in patients with left main coronary artery stenosis one year after percutaneous coronary intervention (PCI).

Methods

Our study included 40 patients who underwent PCI for left main coronary artery stenosis without the use of intravascular ultrasound (IVUS). Patients were followed for a year, and the prognostic effect of PCI on a composite end-point of revascularization, new myocardial infarction, cardiac death, and on all-cause mortality was assessed in multivariable Cox analysis.

Results

The multivariable analysis showed a good prognosis in patients receiving PCI with a total event rate of $7.5 \%$. The independent predictors for major adverse cardiac events (MACE) were diabetes $(p=0.02)$. Other prognostic factors included in the model were gender, age, smoking, body mass index (BMI), hypertension, the complexity of the vessel, and ejection fraction.

Conclusion

PCI for left main coronary artery stenosis without the use of IVUS has a good prognosis after one year of clinical follow-up.

Received 01/29/2018

Review began 02/18/2018

Review ended 06/12/2018

Published 06/22/2018

CC Copyright 2018

Mahmood et al. This is an open access article distributed under the terms of the Creative Commons Attribution License CC-BY 3.0., which permits unrestricted use, distribution, and reproduction in any medium, provided the original author and source are credited.
Categories: Cardiology

Keywords: ischemic heart disease, left main stem, intravascular imaging, percutaneous coronary intervention, coronary artery stenosis

\section{Introduction}

Left main coronary artery disease (LMCAD) is associated with significant morbidity and mortality. The relative risk of perioperative mortality for patients with significant LMCA stenosis compared with patients without LMCAD is 1.3 . The five-year mortality in coronaryartery bypass grafting (CABG) patients with three-vessel disease is $10.7 \%$, compared with $15.8 \%$

How to cite this article

Mahmood M, Altaf A, Salahuddin M, et al. (June 22, 2018) Prognosis of Percutaneous Intervention of a Left Main Coronary Artery Stenosis Without the Use of Intravascular Imaging. Cureus 10(6): e2857. DOI $10.7759 /$ cureus. 2857 
in patients with LMCAD [1-4]. Conventionally, CABG is recommended for most patients with LMCAD [5-6].

However, more recently, randomized trials have shown that percutaneous coronary intervention (PCI) might be an acceptable alternative for such lesions in certain cases [7-10]. This is particularly true in patients with coronary artery disease of low or intermediate anatomical complexity [9]. With recent advances in an improved risk factor profile, careful patient selection, newer drug-eluting stents (DES), and improved intravascular imaging modalities, the use of PCI is expanding.

The aim of this study was an evaluation of clinical outcomes, including unstable angina, myocardial infarction, target vessel revascularization, and death in patients undergoing left main stem stenting without the use of intravascular imaging. Informed consent was taken from all participants in the study which abided by the Declaration of Helsinki.

\section{Materials And Methods}

\section{Enrollment, randomization, and follow-up}

Patients were assessed for eligibility by interventional cardiologists in collaboration with cardiac surgeons. Inclusion criteria included stenosis of the left main coronary artery of $50 \%$ or more, as estimated visually, with a consensus for eligibility for revascularization with either PCI or CABG and patients with a low-to-intermediate anatomical complexity of coronary artery disease (SYNTAX score 32 or less). Exclusion criteria included left main stem disease, along with triple vessel disease, and patients with a high anatomical complexity of coronary artery disease (Synergy Between PCI with Taxus and Cardiac Surgery (SYNTAX) score more than 32).

A history was taken and a detailed examination was done for all patients. Twelve-lead electrocardiography was performed before and after the procedure. Levels of the troponin were measured at the baseline and at 12 and 24 hours after the procedure. Clinical follow-up was performed at one month, six months, and one year. Echocardiography was done at the baseline and then at one year during follow-up. Risk factors were managed according to standard protocols, and guideline-directed medical therapy was recommended for all the patients.

\section{Revascularization strategies and medications}

The technique of performing PCI is described in detail elsewhere [11]. Intravascular ultrasonographic guidance was not used. Drug-eluting stents were deployed in all patients. Anticoagulation was achieved with heparin during the procedure and with glycoprotein (GP) $\mathrm{IIb} / \mathrm{III}$ inhibitors in the initial 12 hours post procedure. Dual antiplatelet therapy was advised for all patients.

\section{Assessment of risk and follow-up for adverse outcomes}

A team of cardiologists was involved in the follow-up of patients. Patients were contacted after a year by telephone, as well as scheduled consultations to assess for adverse events. Three patients were lost to follow-up due to change of permanent address and telephone numbers. Outcomes included in major adverse cardiac events (MACE) were cardiac death, death due to other causes, myocardial infarction, unstable angina, and target vessel revascularization (TVR).

\section{Statistics}

The distribution of variables was assessed using the Kołmogorov-Smirnov test. Statistical analysis results are expressed as the means \pm SD. The t-test and one-way analysis of variance (one-way ANOVA) were performed on normally distributed data. For analysis of nominal data 
and proportions (hypertension, and smoking), the $\mathrm{x} 2$ test was used. Cox proportional hazards analysis were used to identify risk factors for the occurrence of MACE during follow-up. All baseline, demographic, clinical, and angiographic variables were entered into the model. Results are reported as hazard ratios (HRs) and 95\% CIs. All statistical tests were two-tailed, and $p$ values were statistically significant at $<0.05$. All data were analyzed using the Statistical Package for Social Sciences (SPSS) (IBM SPSS Statistics, Armonk, NY), V.20.0 software.

\section{Results}

The mean age of our study sample was $59 \pm 13.02$ years. For the purpose of PCI, only DES (sirolimus, everolimus, rapamycin, zotarolimus) were used. Out of the 40 patients who underwent PCI for left main stem disease, 27 (67.5\%) were men and 13 (32.5\%) were women. Ten patients (25\%) were smokers, while 30 (75\%) were nonsmokers; nine (22.5\%) patients were overweight, 14 (35\%) had diabetes, and 13 (32.5\%) were hypertensive. Four (10\%) of the 40 patients in our study had multivessel disease.

No reflow phenomena were found in any of the patients during the procedure. All 40 (100\%) patients were given adjunctive treatment with GP IIb/ IIIa antagonists in the catheterization laboratory, as well as for $12-24$ hours post-procedure. With regard to maintenance therapy after PCI, 100\% were receiving aspirin, clopidogrel, and nitrates, $97.5 \%$ received beta-blockers, 90\% received angiotensin-converting enzyme inhibitors (ACEI), and $45 \%$ received diuretics. Baseline characteristics for the study sample are shown in Table 1. 


\section{Cureus}

\section{Index}

$\mathrm{Age}^{\mathrm{a}}$

Gender:

Males

Females

Smoking

BMI

Diabetes

Hypertension

Multivessel disease

Ejection Fraction ${ }^{\mathrm{b}}$

Aspirin

Clopidogrel

Beta Blockers

ACEI

Nitrates

Diuretics
Frequency $(\mathrm{n} / \%)$

59

$27 / 67.5$

$13 / 32.5$

$10 / 25$

$9 / 22.5$

14/35

$13 / 32.5$

$4 / 10$

$45 \pm 12$

$40 / 100$

$40 / 100$

39/97.5

$36 / 90$

$40 / 100$

$18 / 45$

\section{TABLE 1: Baseline Characteristics of Patients Included in Study}

${ }^{\text {a }}$ Expressed as mean in years

${ }^{\mathrm{b}}$ Expresses as mean with standard deviation

n: number; BMI: body mass index; ACEI: angiotensin converting enzyme inhibitors

Cumulative MACE for this study was 7.5\% (three patients). The Kaplan Meier analysis is shown in Figure 1. 


\section{Cureus}

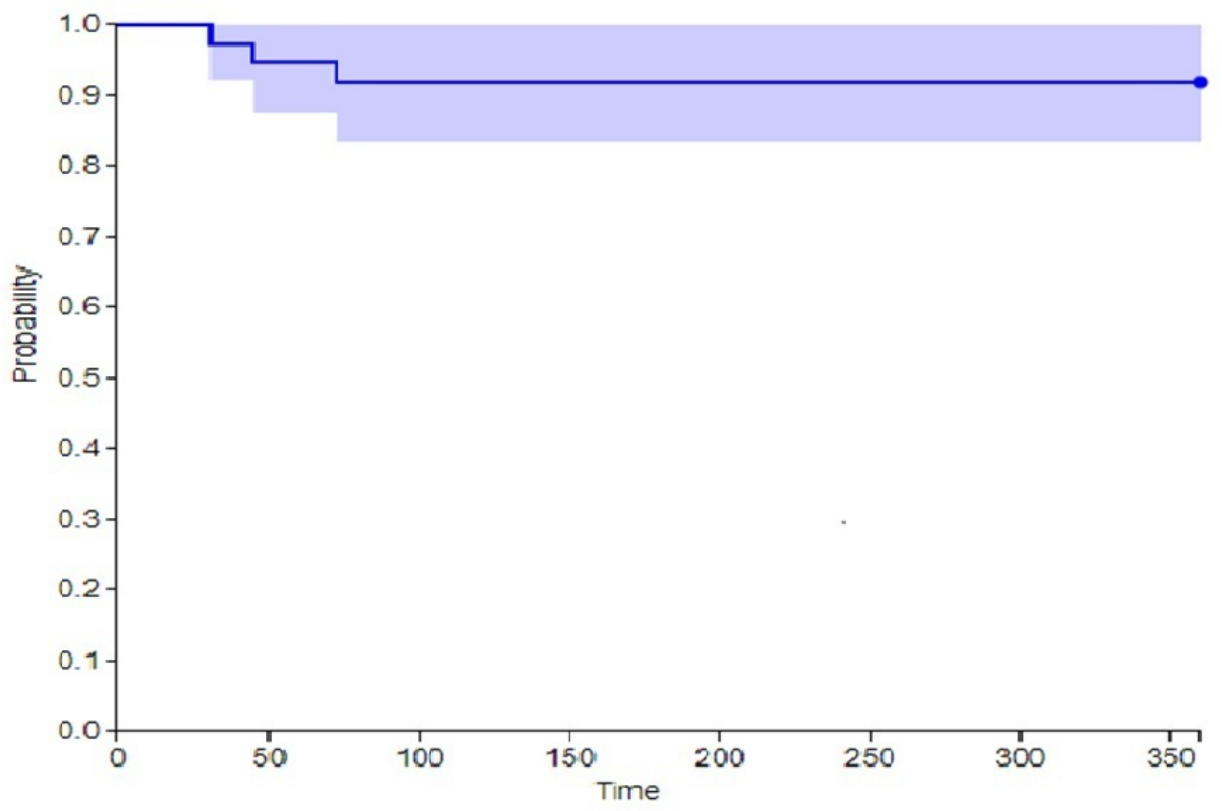

FIGURE 1: Kaplan Meier analysis of subjects included in study

The one-year mortality was $5 \%$ (two patients): myocardial infarction $2.5 \%$ (one patient) and unstable angina episodes $2.5 \%$ (one patient), and no patient had target vessel revascularization. Among the patients with adverse events, one myocardial infarction patient died.

A multivariate Cox regression analysis with risk factors for coronary artery disease as predictive variables and MACE as the dependent variable were carried out. Analysis showed that diabetes $(\mathrm{P}=0.02)$ was an independent predictor of MACE. Variables excluded by the model were age $(\mathrm{P}=$ $0.42)$, gender $(\mathrm{P}=0.75)$, smoking $(\mathrm{P}=0.42)$, body mass index ( $\mathrm{BMI})(\mathrm{P}=0.47)$, hypertension $(\mathrm{P}=$ $0.84)$, ejection fraction $(\mathrm{EF})(\mathrm{P}=0.89)$, and multivessel disease $(\mathrm{P}=0.28)$ as shown in Table 2 . 


\section{Cureus}

\begin{tabular}{|c|c|c|}
\hline Index & Hazard Ratio & $P$ value \\
\hline Age & $1.18(0.81-1.73)$ & 0.42 \\
\hline Gender & $0.94(0.72-1.23)$ & 0.75 \\
\hline Smoking & $1.01(0.99-1.03)$ & 0.42 \\
\hline BMI & $1.08(0.84-1.38)$ & 0.47 \\
\hline Diabetes & $1.51(1.11-2.06)$ & 0.02 \\
\hline Hypertension & $0.96(0.76-1.23)$ & 0.89 \\
\hline Multivessel Disease & $1.18(0.91-1.52)$ & 0.28 \\
\hline Ejection Fraction & $1.03(0.78-1.35)$ & 0.84 \\
\hline
\end{tabular}

\section{TABLE 2: Cox Regression Table With Hazard Ratio For Various Variables}

Cl: confidence interval; BMI: body mass index

\section{Discussion}

Left main stem (LMS) disease has prognostic significance and is found in about $5 \%$ of patients admitted for coronary angiographies [12-13]. The Coronary Artery Surgery Study (CASS) showed significantly improved five-year mortality in CABG as compared to medical therapy (16\% vs 43\%) [14]. CABG is traditionally regarded as the standard treatment for LMS disease, but since the start of PCI era, interventional cardiologists have been rigorously assessing its role in LMS disease.

The high survival rate for post-CABG patients has been shown in multiple studies [15]. However, the Unprotected Left Main Trunk Intervention Multicenter Assessment (ULTIMA) registry demonstrated promising results for PCI to left main stem with $24 \%$ one-year mortality which was even lower in the low-risk group (3.4\%) [16]. Biondi-Zoccai et al. [17] also demonstrated a MACE rate of 10.6 and mortality rate of $5.5 \%$ for PCI patients. Other registries comparing CABG to PCI also demonstrated similar MACE rates [18-19]. Two important aspects that came to light from these registries were the increased rates of target lesion revascularization (TLR) in the PCI group, while there was a higher incidence of cerebrovascular accidents (CVA) in the CABG patients. The Revascularization for Unprotected Left Main Coronary Artery Stenosis: Comparison of Percutaneous Coronary Angioplasty Versus Surgical Revascularization (MAIN-COMPARE) registry [20] also reported similar results.

The Study of Unprotected Left Main Stenting versus Bypass Surgery (LE MANS) was the first randomized controlled trials (RCT) and enrolled 105 patients with significant LMS disease (defined as $>50 \%$ stenosis angiographically) [21]. The primary endpoint was the change in the left ventricular ejection fraction (LVEF) at 12 months, while the secondary endpoint was a major adverse cardiac and cerebrovascular event (MACCE) at 30 days and one year. Surprisingly, there was a statistically significant improvement in LVEF with patients treated with PCI versus CABG (58\% versus 54\%). PCI was also associated with a lower MACE rate at 30 days ( $2 \%$ versus $13 \%$ ) with a MACE being equivalent at one year in the two groups. The study did have a number of limitations, including a small sample size, high use of bare metal stents 
(BMS), and a lower than the contemporary use of left internal mammary artery (LIMA) grafts.

The Synergy Between PCI With Taxus and Cardiac Surgery (SYNTAX) trial was the largest to compare PCI to CABG in LMS disease and demonstrated that if patients were divided into tertiles of syntax score (0-22, 23-32, and above 32), the results were comparable in the lower two tertiles. CABG showed better results as compared to PCI when the syntax score was above $32[22-23]$.

Two recent studies showed conflicting results for coronary artery bypass (CABG) vs percutaneous coronary intervention (PCI) in left main coronary artery (LMCA) disease.

The EXCEL (Evaluation of XCIENCE vs Coronary Artery Bypass Surgery for Effectiveness of Left Main Revascularization) trial demonstrated non-inferiority of PCI with everolimus-eluting stents to CABG in low or intermediate SYNTAX score patients [7]. At three years, the MACE rate was $15.4 \%$ in the PCI group as compared with $14.7 \%$ in the CABG group (95\% confidence interval (CI), 0.79 - 1.26) [7].

The NOBLE (Nordic-Baltic-British Left Main Revascularization) trial found that despite a similar mortality, the five-year MACE was higher after PCI as compared to CABG (28.9\% for PCI vs $19.1 \%$ for CABG) (HR:1.48; 95\% CI, 1.11 - 1.96) [24].

Two important factors which could explain the difference between the two trials were the under-utilization of intravascular ultrasound (IVUS) and use of first-generation stents in 11\% of PCI patients in the NOBLE trial.

A number of factors can influence the outcome of stenting in left main stem diseases, such as lesion location, stent type, use of intravascular imaging, and complexity of lesion. The distal left main disease poses a particularly challenging vessel anatomy to treat [25]. The DrugEluting Stent for Left Main Coronary Artery Disease (DELTA) registry compared ostial/mid-shaft lesions versus distal lesions. The higher rate of TLR was found with distal lesions [26]. In our study, cases with the distal left main disease were relatively fewer, which could explain the good prognosis. Moreover, the Culotte technique appeared to be associated with better outcomes as opposed to the T-stent technique with an in-stent restenosis (ISR) rate of $21 \%$ and $56 \%$ and a TLR rate of $15 \%$ and $56 \%$, respectively [25].

In-stent restenosis and thrombosis are two of the primary concerns in patients coming for PCI. Pandya et al. showed that use of BMS was associated with poorer outcomes than DES [27]. The Intracoronary Stenting and Angiographic Results: Drug-Eluting Stents for Unprotected Coronary Left Main Lesions (ISAR LEFT MAIN and ISAR LEFT MAIN 2) trials were carried out to compare different types of DES [28-29]. These studies proved that outcomes were not influenced by stents (DES) from the same generation.

Appropriate sizing and apposition of stents in LMS disease play an important role in the prevention of ISR and thrombosis. There are no large trials investigating the use of IVUS for PCI but data from certain relatively small studies, such as the MAIN-COMPARE study, point towards improved outcomes with the use of IVUS [30]. In our study, we did not use intravascular imaging due to non-availability of IVUS in our hospital. Patients who agreed to undergo PCI were informed of this limitation. The results in our study were comparable to aforementioned studies, hence showing that absence of intravascular imaging may not be considered a major setback for intervention in left main stem disease.

\section{Limitations}


The sample size was relatively small due to stringent inclusion criteria of our study.

\section{Future}

In recent times, the outcomes of PCI in LMS disease have improved drastically. This can be attributed to improved stent technology, drug-delivery systems, intravascular imaging, and more potent antiplatelet drugs. More randomized controlled trials (RCTs) are required to establish PCI as a standard treatment option for LMS disease in an era dominated by CABG as the gold standard.

\section{Conclusions}

Percutaneous coronary intervention to left main coronary artery stenosis without the use of intravascular imaging showed good prognosis. It would not only save a huge amount of time for physicians during procedures but also prevent a financial burden on patients if they cannot afford intravascular imaging. Hence, more patients will benefit from left main coronary artery interventions, which are considered high-risk by interventionists. Further studies with large sample sizes and longer follow-up will be required to properly ascertain a full prognosis.

\section{Additional Information \\ Disclosures}

Human subjects: Consent was obtained by all participants in this study. Rehman Medical Institute Ethical Review Committee issued approval not applicable. Approved. Animal subjects: All authors have confirmed that this study did not involve animal subjects or tissue. Conflicts of interest: In compliance with the ICMJE uniform disclosure form, all authors declare the following: Payment/services info: All authors have declared that no financial support was received from any organization for the submitted work. Financial relationships: All authors have declared that they have no financial relationships at present or within the previous three years with any organizations that might have an interest in the submitted work. Other relationships: All authors have declared that there are no other relationships or activities that could appear to have influenced the submitted work.

\section{References}

1. Caracciolo EA, Davis KB, Sopko G, et al.: Comparison of surgical and medical group; survival in patients with left main coronary artery disease. Circulation. 1995, 91:2325-34. 10.1161/01.CIR.91.9.2325

2. Chikwe J, Kim M, Goldstone AB, et al.: Current diagnosis and management of left main coronary disease. Eur J Cardiothorac Surg. 2010, 38:420-30. 10.1016/j.ejcts.2010.03.003

3. Rao V, Ivanov J, Weisel RD, et al.: Predictors of low cardiac output syndrome after coronary artery bypass. J Thorac Cardiovasc Surg. 1996, 112(1):38-51. 10.1016/S0022-5223(96)70176-9

4. Jönsson A, Ivert T, Svane B, et al.: Classification of left main coronary obstruction: feasibility of surgical angioplasty and survival after coronary artery bypass surgery. Cardiovasc Surg. 2003, 11(6):497-505. 10.1016/S0967-2109(03)00111-X

5. Fihn SD, Blankenship JC, Alexander KP, et al.: 2014 ACC/AHA/AATS/PCNA/ SCAI/STS focused update of the guideline for the diagnosis and management of patients with stable ischemic heart disease: a report of the American College of Cardiology/ American Heart Association Task Force on Practice Guidelines, and the American Association for Thoracic Surgery, Preventive Cardiovascular Nurses Association, Society for Cardiovascular Angiography and Interventions, and Society of Thoracic Surgeons. J Am Coll Cardiol. 2014, 64:1929-49. 10.1016/j.jacc.2014.07.017

6. Windecker S, Kolh P, Alfonso F, et al.: 2014 ESC/EACTS Guidelines on myocardial revascularization: The Task Force on Myocardial Revascularization of the European Society of Cardiology (ESC) and the European Association for Cardio-Thoracic Surgery (EACTS) 
developed with the special contribution of the European Association of Percutaneous Cardiovascular Interventions (EAPCI). Eur Heart J. 2014, 35:2541-619.

10.1093/eurheartj/ehu278

7. Stone GW, Sabik JF, Serruys PW, et al.: Everolimus-eluting stents or bypass surgery for left main coronary artery disease. NEJM. 2016, 375:2223-35. 10.1056/NEJMoa1610227

8. Cavalcante R, Sotomi Y, Lee CW, et al.: Outcomes after percutaneous coronary intervention or bypass surgery in patients with unprotected left main disease. J Am Coll Cardiol. 2016, 68:9991009. 10.1016/j.jacc.2016.06.024

9. Morice MC, Serruys PW, Kappetein AP, et al.: Five-year outcomes in patients with left main disease treated with either percutaneous coronary intervention or coronary artery bypass grafting in the synergy between percutaneous coronary intervention with taxus and cardiac surgery trial. Circulation. 2014, 129:2388-94. 10.1161/CIRCULATIONAHA.113.006689

10. Capodanno D, Stone GW, Morice MC, et al.: Percutaneous coronary intervention versus coronary artery bypass graft surgery in left main coronary artery disease: a meta-analysis of randomized clinical data. J Am Coll Cardiol. 2011, 58:1426-32. 10.1016/j.jacc.2011.07.005

11. Kappetein AP, Serruys PW, Sabik JF, et al.: Design and rationale for a randomized comparison of everolimus-eluting stents and coronary artery bypass graft surgery in selected patients with left main coronary artery disease: the EXCEL trial. EuroIntervention. 2016, 12:861-72. 10.4244/EIJV12I7A141

12. Rampat R, Hildick-Smith D: Main stem percutaneous coronary intervention - data and ongoing trials. Interventional Cardiology Review. 2015, 10:132-35.

10.15420/icr.2015.10.03.132

13. DeMots H, Rösch J, McAnulty JH, Rahimtoola SH: Left main coronary artery disease. Cardiovasc Clin. 1977, 8:201-11.

14. Yusuf S, Zucker D, Peduzzi P, et al.: Effect of coronary artery bypass graft surgery on survival: overview of 10-year results from randomised trials by the Coronary Artery Bypass Graft Surgery Trialists Collaboration. Lancet. 1994, 344:563-70. 10.1016/S0140-6736(94)91963-1

15. Silvestri M, Barragan P, Sainsous J, et al.: Unprotected left main coronary artery stenting: immediate and mediumterm outcomes of 140 elective procedures. J Am Coll Cardiol. 2000, 35:1543-50. 10.1016/S0735-1097(00)00588-X

16. Tan WA, Tamai H, Park SJ, et al.: Long-term clinical outcomes after unprotected left main trunk percutaneous revascularization in 279 patients. Circulation. 2001, 104:1609-14. 10.1016/j.ahj.2007.10.009

17. Biondi-Zoccai GG, Lotrionte M, Moretti C, et al.: A collaborative systematic review and metaanalysis on 1278 patients undergoing percutaneous drug-eluting stenting for unprotected left main coronary artery disease. Am Heart J. 2008, 155:274-83. 10.1016/j.ahj.2007.10.009

18. Chieffo A, Morici N, Maisano F, et al.: Percutaneous treatment with drug-eluting stent implantation versus bypass surgery for unprotected left main stenosis: a single-center experience. Circulation. 2006, 113:2542-47. 10.1161/CIRCULATIONAHA.105.595694

19. Lee MS, Kapoor N, Jamal F, et al.: Comparison of coronary artery bypass surgery with percutaneous coronary intervention with drug-eluting stents for unprotected left main coronary artery disease. J Am Coll Cardiol. 2006, 47:864-70. 10.1016/j.jcin.2008.02.007

20. Seung KB, Park DW, Kim YH, et al.: Stents versus coronary artery bypass grafting for left main coronary artery disease. N Engl J Med. 2008, 358:1781-92. 10.1056/NEJMoa0801441

21. Buszman PE, Kiesz SR, Bochenek A, et al.: Acute and late outcomes of unprotected left main stenting in comparison with surgical revascularization. J Am Coll Cardiol. 2008, 51:538-45. 10.1016/j.jacc.2007.09.054

22. Serruys PW, Morice MC, Kappetein AP, et al.: Percutaneous coronary intervention versus coronary-artery bypass grafting for severe coronary artery disease. N Engl J Med. 2009, 360:961-72. 10.1056/NEJMoa0804626

23. Sianos G, Morel M, Kappetein AP, et al.: The SYNTAX score: an angiographic tool grading the complexity of coronary artery disease. Eurointervention. 2005, 1:219-27.

24. Mäkikallio T, Holm NR, Lindsay M et al: On behalf of the NOBLE study investigators. NOBLE: a prospective, randomized trial comparing biolimus-eluting stents and bypass graft surgery in selected patients with left main coronary artery disease. Presented at: the 2016 Transcatheter Cardiovascular Therapeutics meeting scientific symposium. Washington, DC; October. 29:2016. 10.1016/S0140-6736(16)32052-9

25. Tiroch K, Mehilli J, Byrne RA et al: Impact of coronary anatomy and stenting technique on 


\section{Cureus}

long-term outcome after drug-eluting stent implantation for unprotected left main coronary artery disease. JACC Cardiovasc Interv. 2014:29-36. 10.1016/j.jcin.2013.08.013

26. Naganuma T, Chieffo A, Meliga E, et al.: Long-term clinical outcomes after percutaneous coronary intervention for ostial/mid-shaft lesions versus distal bifurcation lesions in unprotected left main coronary artery: the DELTA Registry (drug-eluting stent for left main coronary artery disease): a multicenter registry evaluating percutaneous coronary intervention versus coronary artery bypass grafting for left main treatment. JACC Cardiovasc Interv. 2013, 6:1242-49. 10.1016/j.jcin.2013.08.005

27. Pandya SB, Kim YH, Meyers SN, et al.: Drug-eluting versus bare-metal stents in unprotected left main coronary artery stenosis a meta-analysis. JACC Cardiovasc Interv. 2010, 3:602-11. 10.1016/j.jcin.2010.03.019

28. Mehilli J, Kastrati A, Byrne RA, et al.: Paclitaxel- versus sirolimus-eluting stents for unprotected left main coronary artery disease. J Am Coll Cardiol. 2009, 53:1760-68. 10.1016/j.jacc.2009.01.035

29. Mehilli J, Richardt G, Valgimigli M, et al.: Zotarolimus- versus everolimus-eluting stents for unprotected left main coronary artery disease. J Am Coll Cardiol. 2013, 62:2075-82. 10.1016/j.jacc.2013.07.044

30. Park SJ, Kim YH, Park DW, et al.: Impact of intravascular ultrasound guidance on long-term mortality in stenting for unprotected left main coronary artery stenosis. Circ Cardiovasc Interv. 2009, 2:167-77. 10.1161/CIRCINTERVENTIONS.108.799494 